\title{
BMJ Open Cross-sectional online survey to determine the prevalence, knowledge, attitude and practice of tobacco cessation among governmental healthcare workers in Qatar
}

\author{
Ahmad AIMulla, Silva Kouyoumjian (D), Nour EINakib
}

To cite: AlMulla A, Kouyoumjian S, EINakib N. Cross-sectional online survey to determine the prevalence, knowledge, attitude and practice of tobacco cessation among governmental healthcare workers in Qatar. BMJ Open 2021;11:e044379. doi:10.1136/ bmjopen-2020-044379

- Prepublication history for this paper is available online. To view these files, please visit the journal online (http://dx.doi. org/10.1136/bmjopen-2020044379).

Received 02 September 2020 Revised 03 March 2021 Accepted 09 March 2021
Check for updates

(c) Author(s) (or their employer(s)) 2021. Re-use permitted under CC BY-NC. No commercial re-use. See rights and permissions. Published by BMJ.

Medicine, Tobacco Control Center, WHO Collaborative Center, Hamad Medical Corporation, Doha, Qatar

Correspondence to Silva Kouyoumjian; SKouyoumjian@hamad.qa

\section{ABSTRACT}

Objectives One effective approach of tobacco control is to encourage the role and the participation of healthcare workers in the prevention efforts against tobacco use. This study aimed to determine the prevalence of tobacco use among governmental healthcare workers in Qatar, to assess healthcare workers' knowledge, attitude and practice of tobacco cessation and to predict factors associated with above average tobacco cessation practice scores.

Design A cross-sectional survey study was conducted among healthcare workers working in Hamad Medical Corporation and Primary Healthcare Centres in Qatar using a self-administered online questionnaire in 2019.

Setting Hamad Medical Corporation and Primary Healthcare Centres in Qatar.

Participants Governmental healthcare workers aged 18 years and above $(n=7214)$.

Results The response rate of our online survey was $20.6 \%(7214 / 35000)$. Of the 7214 healthcare workers, $16.3 \%$ ( $n=1178$ ) were current tobacco users. In particular, the prevalence of tobacco use among physicians was $11.0 \%$. Fifty-two per cent of healthcare workers $(n=2338)$ attained an average knowledge score (12-17), 71.8\% $(n=3094)$ attained positive attitude scores (8-12) and $57.1 \%(n=3052)$ attained above average practice scores (12-26). Among the different professions, physicians were having the highest mean knowledge $(15.3 \pm 4.7)$, attitude $(9.4 \pm 1.9)$ and practice $(13.7 \pm 6.1)$ scores. Multivariate analysis showed that having good knowledge (adjusted OR $(A O R)=2.8 ; p<0.0001)$ and training $(A O R=2.4 ; p<0.0001)$ were the strongest factors associated positively with above average tobacco cessation practice scores.

Conclusions Healthcare workers in Qatar have a relatively similar prevalence of tobacco use than earlier studies with no significant increase. Investing more in training programmes for healthcare workers are needed to root out this negative behaviour and to increase their skills to assist users to quit.

\section{INTRODUCTION}

The global tobacco epidemic is one of the main public health threats that our world has ever faced. One effective approach of
Strengths and limitations of this study

- This is a cross-sectional study, with an expected response rate for an online survey examining the prevalence of tobacco use among governmental healthcare workers in Qatar including, but not limited to physicians, nurses, physicians, dentists, pharmacists and others.

- This is the first survey to investigate the knowledge, attitude and practice of tobacco cessation of healthcare workers representative of the governmental healthcare sector in Qatar.

- Healthcare workers in the private healthcare sector were not included in this study.

- Causal relationships cannot be established due to the cross-sectional design of the study.

- To reduce sampling and non-response bias, we shared our survey through text message, and we sent several reminders.

tobacco control is to encourage the key role of healthcare workers (HCWs), ${ }^{1}$ to promote cessation and treatment using evidence-based tobacco cessation guidelines. ${ }^{2}$ They have a unique position to provide information about quitting, since they can reach large number of patients. ${ }^{3}$ As health promoters, HCW should set an example by not using tobacco as most patients perceive them as their role models, in line with the guidelines of WHO Framework Convention on Tobacco Control (FCTC) Article 14. ${ }^{4}$ Nevertheless, HCWs who are using tobacco represent an important challenge, as they may have negative attitudes that prevent them from providing advice on the benefits of quitting. ${ }^{5}$

Research indicates that implementation of tobacco cessation intervention is impeded by inadequate training and staff support for HCWs, lack of knowledge about the effects of tobacco on health, and lack of experience 
in providing counselling and tobacco cessation assistance. ${ }^{67}$

Qatar, has ratified the WHO FCTC since 2004, where tobacco legislation has been introduced and comprehensive tobacco control measures are being implemented to reduce tobacco consumption and its hazards, in line with Qatar National Vision 2030. ${ }^{8}$

On 2003, 603 physicians in Qatar completed the WHO Health Professionals Survey, where only 7\% smoked occasionally and just $5 \%$ smoked regularly. ${ }^{9}$ To update the current prevalence of tobacco use among HCW in Qatar, Tobacco Control Centre, a WHO Collaborative Centre at Hamad Medical Corporation (HMC) aimed to conduct an online survey specifically, (1) to determine the prevalence of tobacco use among HCW representative of the governmental healthcare sector in Qatar, (2) to determine the knowledge, attitude and practice of tobacco cessation of HCW in Qatar and (3) to predict factors associated with above average tobacco cessation practice scores to assess training needs of HCW on tobacco cessation programmes.

\section{METHODOLOGY}

\section{Study design and population}

This was a cross-sectional research study representative of governmental HCW including physicians, nurses, pharmacists, dentists and others (allied health support staff and employees) in Qatar. To be eligible to participate, participants had to be at least 18 years old, working in HMC, a large Joint Commission International accredited group of tertiary hospitals in Qatar, or in Primary Healthcare Centres (PHCC), providing its services through 27 centres. The number of HCW at the time was around 30000 in HMC, while it was about 5000 in PHCC. The study was conducted between 13 October 2019 and 30 November 2019.

\section{Recruitment}

A self-selected sampling strategy was applied. Participants were recruited voluntarily to participate through the weekly HMC/PHCC newsletter announcements, which contained the web link to the online questionnaire. The newsletters are published on HMC/PHCC online portals, where employees' can access them through their corporate emails. A total of seven survey announcements were issued beginning of each week every Sunday starting on 13 October 2019 till 24 November 2019. It included a description of the survey explaining the purpose of the study and specific instructions for completing the anonymous online questionnaire. Several survey reminders were sent through text messages. Once the respondent filled out the online survey, we considered that the respondent agreed to participate in the study and provided the informed consent. Completing the questionnaire took an average of $15 \mathrm{~min}$.

\section{Instrument and measures}

The self-administered online survey was constructed based on WHO Global Health Professional Survey that was previously used in Qatar, ${ }^{9}$ with modifications to assess the knowledge, attitudes, and practice patterns of HCW in relation to tobacco cessation based on validated instruments used in prior studies. ${ }^{210-12}$ To make sure that the instrument was suitable for the population, it was pilot tested with random 20 HMC HCWs and was modified according to their comments. It was suggested to define what is daily just under the survey question as a footnote. The wording of some questions and statements were edited.

The online survey consisted of two parts. The first part collected information about HCWs': sociodemographic characteristics and tobacco use. In the present study, definition of current tobacco use includes both daily and occasional use. Daily use meaning at least one tobacco product every day (regular) and occasional use at least one tobacco product not every day measured weekly (social). The second part of the survey involved only HCW who had direct patient care in order to assess their current tobacco cessation practice based on the model ask, advise, assess, assist and arrange follow-up, attitude towards their role in counselling patients, and knowledge towards provision of tobacco cessation. For reasons of length, a selected number of these items are discussed in the present study.

Practice scores were derived from 12 questions, where two points were awarded for 'always', 1 point for 'sometimes' and 0 points for 'never'. Possible scores ranged from 0 to 24 ( $\geq 12$ were classified as 'above average' practice, while $\leq 11$ as 'below average'). Knowledge scores were derived as the sum of the correct responses to 24 questions, with 1 point assigned for each correct response and 0 for each incorrect/don't know response. Respondents scoring $\geq 18$ were categorised as having 'good knowledge', those scoring 12-17 as having 'average knowledge' and those $\leq 11$ as having 'poor knowledge'.

Attitude scores were derived from 12 questions. A score of 1 was given for responses agreeing with positively worded statements/disagreeing with negatively worded statements, while a score of 0 was given for responses disagreeing with positively worded statements/agreeing with negatively worded statements. Respondents with a total score of $8 \geq$ were categorised as having "positive attitudes' and those with a total score of $\leq 7$ as having 'negative attitudes'.

\section{Patient and public involvement}

There was no patient or public involvement in the study design or conduct of this study. We shared a newsletter thanking all the participants for their time and effort. We intend to share our findings in the media after publication.

\section{Data analysis}

SPSS V.26 was used for statistical analysis. The t-test was used to determine whether there was a significant difference between the means of knowledge, attitude and practice scores. Pearson's $\chi^{2}$ test was used to determine the 
association of various variables with level of practice of smoking cessation. The multivariate logistic regression method was used to predict factors associated with above average tobacco cessation practice scores. A $\mathrm{p}<0.05$ was considered significant.

\section{RESULTS}

\section{Sample characteristics}

Of the 7897 questionnaires, 683 were incomplete and were excluded from the analysis leaving a total of 7214 questionnaires $(\mathrm{HMC}=6232$, $\mathrm{PHCC}=982)$, proportional to the actual sample sizes of both institutions of about $20 \%$ and giving a response rate of $20.6 \%$ (7214/35 000).

The sample included $3185(44.2 \%)$ males and 4029 (55.8\%) females, giving a male to female ratio of about 1 to 1 . Almost half of the respondents $(46 \%)$ were between 25 and 34 years of age. About half of the respondents $(48.8 \%)$ had been in practice for more than 10 years. Only $12.0 \%$ of the respondents had zero hours of patient care per week. Sixty-two per cent of the participants were nurses, physicians $(8 \%)$, pharmacists $(3 \%)$, dentists $(1 \%)$ and others $(27 \%)$ (table 1$)$.

\section{Current tobacco use}

The prevalence of current tobacco use among HCW was $16.3 \%(\mathrm{n}=1178)$, with $7.7 \%(\mathrm{n}=557)$ reporting as daily users and $8.6 \%(\mathrm{n}=621)$ as occasional users. In particular, the prevalence of tobacco use among physicians was $11.0 \%, 10.9 \%$ among nurses, $29.5 \%$ among dentists, $12.7 \%$ among pharmacists and $17.6 \%$ among others. Out of the 3185 males, $30.7 \%(n=978)$ reported that they were current tobacco users and out of 4029 females only 5.0\% $(\mathrm{n}=200)$ reported current tobacco use. Table 1 shows sample characteristics by current tobacco use.

\section{Knowledge, attitude and practice scores on tobacco cessation}

\section{Knowledge of HCWs on tobacco cessation}

Knowledge scores ranged from 0 to 23 (Mean=12.4; $\mathrm{SD}=4.2 ; \mathrm{N}=4477)$. Almost $40 \%(\mathrm{n}=1710)$ of the respondents attained a poor knowledge score (0-11), 52.2\% $(\mathrm{n}=2338)$ attained an average knowledge score (12-17), while $9.6 \%(\mathrm{n}=429)$ attained a good knowledge score (18-24) (figure 1).

Eighty-three per cent of the respondents stated that tobacco smoking was a chronic disorder associated with relapse. Fifty-six per cent stated that all patients should be asked about their smoking history whether they have or do not have a smoking related disease. Only $30.0 \%$ of the respondents reported that brief intervention is effective. However, $84.8 \%$ of the respondents stated that cessation advice by a healthcare provider increases the patient's chances of quitting. Nicotine gum, nicotine patch and nicotine lozenge were identified as recommended cessation medications by $65.9 \%, 68.7 \%$ and $40.0 \%$, respectively. Only $27.8 \%$ and $25.3 \%$ of the respondents identified bupropion and varenicline tablets as smoking cessation medications (table 2).

\section{Attitude of HCWs on tobacco cessation}

The attitude scores ranged from 0 to 12 (mean $=8.75$; $\mathrm{SD}=1.96 ; \mathrm{N}=4309)$. Most respondents $(71.8 \% ; \mathrm{n}=3094)$ attained positive attitude scores (8-12), while $28.2 \%$ of the respondents' $(\mathrm{n}=1215)$ attained negative attitude scores (0-7) (figure 1).

Almost all respondents agreed that it was their responsibility to motivate $(94.5 \%)$, assist patients to quit $(93.1 \%)$ and discuss benefits of tobacco cessation (94.0\%). Most respondents $(88.7 \%)$ perceived that counselling improves the relationship with patients, however, $51.0 \%$ thought that patients are not receptive to receiving tobacco cessation. Eighty-four per cent reported that their patients' health problems take precedence over tobacco cessation counselling, with $57.1 \%$ reporting that they do not have enough time to advice all tobacco users (table 2).

\section{Practice of HCWs on tobacco cessation}

The practice scores ranged from 0 to 26 (mean $=13.34$; $\mathrm{SD}=7.4 ; \mathrm{N}=5343)$. Forty-three per cent $(\mathrm{n}=2291)$ of the respondents obtained below average practice scores $(0-11)$ while, $57.1 \% \quad(\mathrm{n}=3052)$ attained above average practice scores (12-26) (figure 1).

Half of the respondents inquired about the patients smoking status and always recorded the patient's smoking status. More than half of the respondents $(51.5 \%)$ stated that they always advised smokers to quit, with half of them discussing risks and benefits of quitting with them. Onefifth of the respondents stated that they always discussed the use of nicotine replacement therapy and medications, while only $17.8 \%$ stating that they always set up a date to review the progress of their patients (table 2).

There were statistically significant differences in the mean knowledge $(p<0.0001)$, attitude $(p<0.0001)$ and practice $(p<0.0001)$ scores among the different professions (table 3A). The mean knowledge scores were 12.3 $( \pm 3.9), 15.3( \pm 4.7), 10.4( \pm 5.2), 14.9( \pm 3.8), 11.2( \pm 4.4)$ for nurses, physicians, dentists, pharmacists and others, respectively. The mean attitude scores were $8.8( \pm 2.0)$, $9.4( \pm 1.9), 8.1( \pm 2.7), 8.7( \pm 2.1), 8.3( \pm 2.3)$ for nurses, physicians, dentists, pharmacists and others, respectively. The mean practice scores were $14.4( \pm 7.4), 13.7$ $( \pm 6.1), 11.5( \pm 6.7), 11.2( \pm 6.3), 9.9( \pm 7.2)$ for nurses, physicians, dentists, pharmacists and others, respectively (table 3A).

There were statistically significant differences in the mean knowledge $(p<0.0001)$, attitude $(p<0.0001)$ and practice $(\mathrm{p}=0.014)$ scores among HMC and PHCC HCWs (table 3B). The mean knowledge score for HMC was 12.2 $( \pm 4.1)$ and $13.6( \pm 4.7)$ for PHCC. The mean attitude score was $8.7( \pm 2.0)$ for HMC and $9.0( \pm 1.9)$ for PHCC. The mean practice score was $13.2( \pm 7.4)$ for HMC and $14.0( \pm 7.4)$ for PHCC (table 3B). 
Table 1 Healthcare workers' sociodemographic characteristics by current tobacco use

\section{Sample description}

Gender

Male

Female

Marital status

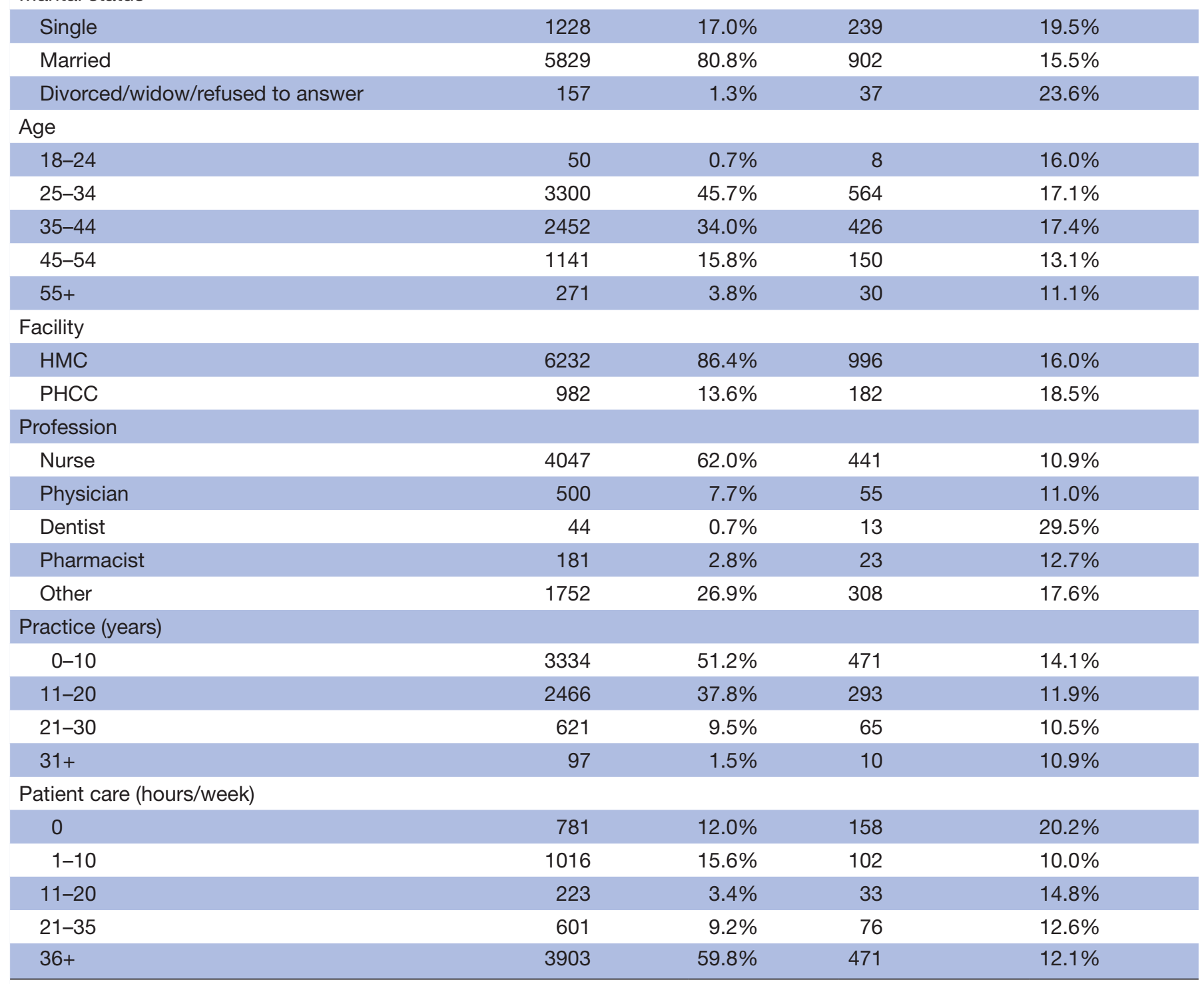

*Total do not add up due to missing data.

†Includes daily and occasional users.

HMC, Hamad Medical Corporation; PHCC, Primary Healthcare Corporation.

Total ${ }^{*} \mathrm{~N}=7214$

\section{Current tobacco users $\uparrow \mathrm{N}=1178$}

3185

4029

$44.2 \%$

978

$30.7 \%$

$55.8 \%$

200

$5.0 \%$

1228

$17.0 \%$

239

$19.5 \%$

Married

5829

$80.8 \%$

902

$15.5 \%$

Age

\section{Predictive factors for above average tobacco cessation practice scores}

In multivariate analysis (table 4), respondents with good knowledge scores were three times (adjusted OR $(\mathrm{AOR})=2.8 ; \mathrm{p}<0.0001)$, and those with average knowledge scores were two times $(\mathrm{AOR}=1.7 ; \mathrm{p}<0.0001)$, more likely to have above average practice scores as compared with those with poor knowledge scores.

HCWs who were using tobacco were less likely to have above average practice scores as compared with non-smokers, specifically daily smokers $\quad(\mathrm{AOR}=0.7$; $\mathrm{p}=0.026$ ). Males were more likely to have above average practice scores as compared with females $(\mathrm{AOR}=1.4$; $\mathrm{p}<0.0001)$. Nurses were three times $(\mathrm{AOR}=2.9 ; \mathrm{p}<0.0001)$ and physicians were about two times more likely $(\mathrm{AOR}=1.6 ; \mathrm{p}=0.001)$ to have above average practice scores as compared with others.

Respondents who stated that they had received training on tobacco cessation and who stated that pamphlets were available in healthcare facilities were more likely to 
$70 \%$

$60 \%$

$50 \%$

$52.2 \%$

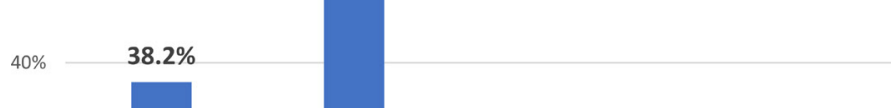

$30 \%$

$0 \%$

-

$0 \%$

$0 \%$

Poor Knowledge

Average Knowledge

Good Knowledge

\begin{abstract}
$9.6 \%$
\end{abstract}

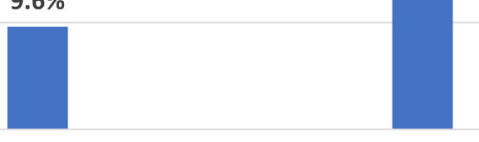

Positive Attitude

Negative Attitude

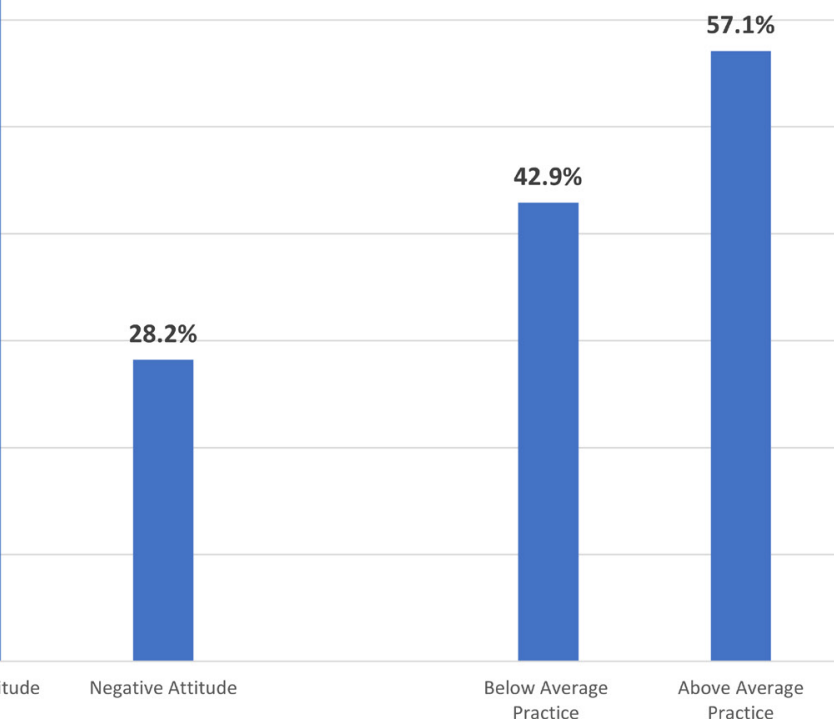

Figure 1 Summary of knowledge, attitude and practice scores of tobacco cessation of healthcare workers.

have above average practice scores $(\mathrm{AOR}=2.4 ; \mathrm{p}<0.0001$; $\mathrm{AOR}=1.6 ; \mathrm{p}<0.0001)$, respectively.

\section{DISCUSSION}

Using an online cross-sectional survey, we determined the prevalence of tobacco use among governmental HCWs in Qatar, fortunately, $83.7 \%$ reported that they had never used tobacco at all. We assessed HCWs' knowledge, attitude and practice of tobacco cessation and predicted factors associated with it-all for the purpose of informing decision making in tobacco control programmes involving HCW for reducing smoking prevalence and improving public health. Mainly, the results demonstrated that major gains can be attained through better knowledge and training of HCW to increase cessation intervention practice and quit attempt. To our knowledge, such an analysis has not been carried out in Qatar before and provides a foundation for future research.

The results of this study showed that $16.3 \%$ of HCW were current tobacco users, however current tobacco use, among physicians only was $11.0 \%$ lower than earlier studies conducted among physicians in 2003 (12\% smoking: daily $5 \%$ and occasionally $7 \%)^{9}$ and in 2007 (15.8\% current smoking).$^{13}$ It was slightly higher than studies reporting prevalence among physicians in Bahrain $(8.6 \%)^{14}$ and in Oman (6.9\%). ${ }^{15}$ Moreover, low current tobacco use was also reported among nurses in our sample $(10.9 \%)$, where $36.1 \%$ of nurses and $46.9 \%$ of physicians in Jordan were current smokers, ${ }^{16}$ and $25.6 \%$ of nurses and $35.9 \%$ of physicians at the Prince Mohammed Bin Abdulaziz Hospital in Riyadh, Saudi Arabia were smokers. ${ }^{17}$ Furthermore, current tobacco use of HCW was less than a worldwide pooled prevalence of tobacco use in HCWs, based on a systematic review and meta-analysis $(21 \%) .{ }^{18}$ Much lower than other regional studies, where $26.3 \%$ of governmental HCWs in Abha city were tobacco users ${ }^{19}$ and $22 \%$ of Saudi dental students were smokers. ${ }^{20}$ High rates of smoking among physicians and other HCWs may compromise their ability to effectively treat patients addicted to smoking, ${ }^{21}$ fortunately this is not the case in Qatar. The observed decreasing trend may be related to the expansion of the tobacco dependence treatment services across Qatar such as primary healthcare facilities, hospitals, specialised cessation centres with full cost of cessation support and treatment. ${ }^{22}$

The prevalence of tobacco use among males was six times higher than the prevalence among female respondents consistent with previous studies, ${ }^{9}{ }^{23}$ where smoking among women is not generally accepted culturally in Qatar, similar to a trend observed in other Arab countries. $^{24}$

Overall, half of HCW had an average level of knowledge on tobacco cessation. Large number of HCW had a positive attitude towards the provision of smoking cessation $(72 \%)$, projecting a positive image to the patients and to the society in Qatar; while more importantly, about $60 \%$ of HCW routinely provided tobacco cessation interventions to their patients, whereby being effective in helping users to quit. This could be due to the collective efforts of Tobacco Control Centre-WHO Collaborating Centre, the Ministry of Public Health in Qatar and PHCC, which has been remarkably active in organising multiple regional training sessions to build capacities on nicotine dependence treatment among HCW with the collaboration of international organisations like $\mathrm{WHO}$ and others. ${ }^{25}$ 
Table 2 Knowledge, attitude and practice of tobacco cessation of healthcare workers

\begin{tabular}{|c|c|c|}
\hline Knowledge $\mathrm{N}=4477$ & Response & n (\%) \\
\hline Tobacco dependence is a chronic disease associated with relapse & True & 3699(82.6) \\
\hline $\begin{array}{l}\text { Patients should only be asked about their smoking history if they have a smoking related } \\
\text { disease/illness }\end{array}$ & False & $2521(56.3)$ \\
\hline Brief intervention is ineffective & False & $1342(30.0)$ \\
\hline $\begin{array}{l}\text { Smoking cessation advice given by a health professional to a patient increases the } \\
\text { patient's chances of quitting }\end{array}$ & True & $3797(84.8)$ \\
\hline Nicotine patches are recommended & True & $3077(68.7)$ \\
\hline Nicotine lozenges are recommended & True & 1792(40.0) \\
\hline Bupropion tablets are recommended & True & $1245(27.8)$ \\
\hline Varenicline tablets are recommended & True & $1134(25.3)$ \\
\hline It is my responsibility to assist patients to quit smoking & Agree & $4011(93.1)$ \\
\hline It is my role to discuss the benefits of smoking cessation with patients & Agree & $4050(94.0)$ \\
\hline $\begin{array}{l}\text { My patients' acute health problems take precedence over smoking cessation counselling/ } \\
\text { advice }\end{array}$ & Agree & $3596(83.5)$ \\
\hline Smoking cessation counselling improves my relationship with patients & Agree & $3823(88.7)$ \\
\hline $\begin{array}{l}\text { Patients are not receptive to receiving smoking cessation assistance from healthcare } \\
\text { providers }\end{array}$ & Agree & $2199(51.0)$ \\
\hline $\begin{array}{l}\text { I do not have enough time to provide advice and counselling to all my patients who smoke } \\
\text { during routine consultations }\end{array}$ & Agree & $2460(57.1)$ \\
\hline \multicolumn{3}{|l|}{ Practice $\mathrm{N}=5343$} \\
\hline Therapy/medications with patients & Always & 1068(20.0) \\
\hline Set up a follow-up appointment to review the progress of patients on quitting smoking & Always & $952(17.8)$ \\
\hline
\end{tabular}

The impact of these trainings was evident when comparing the mean knowledge, practice and attitude scores among the different professions, where there were statistically significant differences, with physicians having the highest mean scores. Physicians and pharmacists had the highest mean knowledge scores followed by nurses, dentists and others. Physicians and nurses had the highest mean practice scores followed by dentists, pharmacists and others. All professions somewhat had comparable mean attitude scores with physicians scoring the highest. HCW in HMC and PHCC had comparable mean knowledge, practice and attitude scores.

Most HCWs in our study were familiar with the chronic and addictive nature of tobacco $(82.6 \%)$. This ensures that they motivate their patients to keep trying even after relapse, since users require continuous efforts rather than onetime care. ${ }^{2}$ They were also aware of the benefits of providing advice about quitting $(84.8 \%)$ in agreement with a study conducted among healthcare professionals in Jordan. ${ }^{26}$ However, $70 \%$ of HCW reported that brief intervention is ineffective. It is important that they offer brief advise as part of their routine consultations increasing the chances of success attempts to quitting, ${ }^{27} 28$ in line with the Offer help to quit tobacco use measure of MPOWER. ${ }^{29}$

The lack of awareness of medications used to assist users to quit limits the ability of HCW to effectively discuss such treatment options with smokers. Similar findings were observed in a study among nurses and physicians working in a tertiary hospital in Armenia, where awareness about pharmacological cessation aids was limited. ${ }^{30}$

HCW had a positive attitude towards their role comparable to a study among healthcare providers in Palestine, where more than $80 \%$ of the sample agreed that they should advise patients to quit smoking. ${ }^{31}$ However, $51.0 \%$ of HCW reported that patients were unwilling to receive 
Table 3 Comparison of mean knowledge, attitude and practice scores of healthcare workers (A) by profession and (B) by facility

\begin{tabular}{|c|c|c|c|c|c|}
\hline (A) & $\mathbf{N}$ & Mean & SD & $\mathbf{F}$ & $P$ value \\
\hline Knowledge scores & 4477 & 12.37 & 4.18 & 81.596 & $<0.0001$ \\
\hline Nurse & 3108 & 12.27 & 3.85 & & \\
\hline Physician & 392 & 15.25 & 4.65 & & \\
\hline Dentist & 38 & 10.37 & 5.18 & & \\
\hline Pharmacist & 106 & 14.92 & 3.75 & & \\
\hline Other† & 833 & 11.17 & 4.38 & & \\
\hline Attitude scores & 4309 & 8.75 & 1.96 & 20.997 & $<0.0001$ \\
\hline Nurse & 2998 & 8.8 & 1.82 & & \\
\hline Physician & 378 & 9.38 & 1.94 & & \\
\hline Dentist & 36 & 8.11 & 2.67 & & \\
\hline Pharmacist & 102 & 8.69 & 2.06 & & \\
\hline Other† & 795 & 8.32 & 2.27 & & \\
\hline Practice scores & 5343 & 13.34 & 7.43 & 84.119 & $<0.0001$ \\
\hline Nurse & 3645 & 14.4 & 7.38 & & \\
\hline Physician & 460 & 13.73 & 6.09 & & \\
\hline Dentist & 42 & 11.52 & 6.7 & & \\
\hline Pharmacist & 148 & 11.22 & 6.3 & & \\
\hline Other† & 1048 & 9.88 & 7.18 & & \\
\hline (B) & $\mathbf{N}$ & Mean & SD & $\mathbf{F}$ & $P$ value \\
\hline Knowledge scores & 4477 & 12.37 & 4.18 & & \\
\hline HMC & 3886 & 12.18 & 4.07 & 61.151 & $<0.0001$ \\
\hline $\mathrm{PHCC}$ & 591 & 13.61 & 4.66 & & \\
\hline Attitude scores & 4309 & 8.75 & 1.96 & & \\
\hline $\mathrm{HMC}$ & 3737 & 8.71 & 1.95 & 13.74 & $<0.0001$ \\
\hline PHCC & 572 & 9.03 & 1.95 & & \\
\hline Practice scores & 5343 & 13.34 & 7.43 & & \\
\hline $\mathrm{HMC}$ & 4636 & 13.25 & 7.43 & 6.036 & 0.014 \\
\hline PHCC & 707 & 13.98 & 7.42 & & \\
\hline
\end{tabular}

${ }^{*}$ Factors with $p<0.05$ were considered statistically significant.

$\dagger$ Allied health support staff and employees.

HMC, Hamad Medical Corporation; PHCC, Primary Healthcare Centres.

advice on smoking cessation. Some smokers desire to maintain personal control over their smoking behaviour and other heavy smokers are more resistant to accepting quitting support and among many other factors. ${ }^{32}$ It is therefore important to address how to handle such barriers in future trainings.

In our study, $57.1 \%$ perceived that they did not have enough time to provide advice to smokers and $83.5 \%$ agreed that patients' other health problems took precedence to provision of smoking cessation counselling. This could be explained by lack of appropriate training on tobacco cessation counselling as found in another study, where oncologists used to delegate the counselling role to other specialists, such as primary healthcare providers or cardiologists. ${ }^{30}$ This suggests the need to sensitise HCW that even minimal intervention of $1 \mathrm{~min}$ would increase overall tobacco abstinence rate when compared with no intervention at all. ${ }^{33}$ Concerns about time constraints and competing health priorities need to be addressed by training HCW, which are frequently reported as major barriers. ${ }^{32} 34$

The first step in the provision of tobacco cessation is the identification and documentation of a patient's tobacco use status, which is still not a common practice in the region. ${ }^{25}$ Half of the respondents reported always asking patients about their smoking status and routinely advised them to quit, same as another study in Jordan. ${ }^{35}$ Lack of knowledge on tobacco cessation medications by the study participants may account for the high number of HCW that never discussed the use of pharmacotherapy. Consistent with other studies, beyond screening for smoking and offering advice to quit further efforts are needed to assess, assist and arrange follow-up with patients to quit smoking. ${ }^{35} 36$ 
Table 4 Predictive factors for above average tobacco cessation practice scores for healthcare workers $\nmid$

\begin{tabular}{|c|c|c|c|c|c|c|}
\hline \multirow{2}{*}{ Predictors } & & \multirow{2}{*}{$\mathbf{N}$} & \multirow{2}{*}{ Adjusted OR } & \multicolumn{2}{|l|}{$95 \% \mathrm{Cl}$} & \multirow{2}{*}{$P$ value } \\
\hline & & & & Lower & Upper & \\
\hline \multirow[t]{3}{*}{ Knowledge levels } & Poor & 1625 & 1.0 (Ref) & & & \\
\hline & Average & 2263 & 1.669 & 1.457 & 1.912 & $<0.0001^{*}$ \\
\hline & Good & 421 & 2.769 & 2.122 & 3.615 & $<0.0001^{*}$ \\
\hline \multirow[t]{2}{*}{ Attitude levels } & Negative & 1215 & 1.0 (Ref) & & & \\
\hline & Positive & 3094 & 1.149 & 0.994 & 1.327 & 0.06 \\
\hline \multirow[t]{2}{*}{ Gender } & Female & 2552 & 1.0 (Ref) & & & \\
\hline & Male & 1787 & 1.356 & 1.169 & 1.573 & $<0.0001^{*}$ \\
\hline \multirow[t]{3}{*}{ Smoking status } & Not at all & 3775 & 1.0 (Ref) & & & \\
\hline & Daily & 260 & 0.729 & 0.551 & 0.963 & $0.026^{*}$ \\
\hline & Occasionally & 274 & 0.906 & 0.692 & 1.187 & 0.474 \\
\hline \multirow[t]{2}{*}{ Training } & No & 3874 & 1.0 (Ref) & & & \\
\hline & Yes & 435 & 2.394 & 1.867 & 3.068 & $<0.0001^{*}$ \\
\hline \multirow[t]{2}{*}{ Pamphlets/brochures } & No & 2679 & 1.0 (Ref) & & & \\
\hline & Yes & 1630 & 1.621 & 1.41 & 1.864 & $<0.0001^{*}$ \\
\hline \multirow[t]{5}{*}{ Profession } & Other & 795 & 1.0 (Ref) & & & \\
\hline & Nurse & 2998 & 2.913 & 2.441 & 3.476 & $<0.0001^{*}$ \\
\hline & Physician & 378 & 1.603 & 1.221 & 2.104 & $0.001^{*}$ \\
\hline & Dentist & 36 & 1.336 & 0.657 & 2.717 & 0.424 \\
\hline & Pharmacist & 102 & 0.901 & 0.578 & 1.404 & 0.644 \\
\hline \multirow[t]{2}{*}{ Current workplace } & PHCC & 572 & 1.0 (Ref) & & & \\
\hline & $\mathrm{HMC}$ & 3737 & 0.845 & 0.685 & 1.042 & 0.114 \\
\hline
\end{tabular}

${ }^{*}$ Factors with $\mathrm{p}<0.05$ were considered statistically significant.

†Includes also allied health support staff and employees who had direct patient care.

HMC, Hamad Medical Corporation; PHCC, Primary Healthcare Corporation.

Our study showed that above average tobacco cessation practice scores was associated with knowledge level, training, organisational support, gender, smoking status and profession as confirmed in the literature. ${ }^{6} 21353738$ Having good knowledge and training were the strongest factors associated positively with tobacco cessation practices among HCW in Qatar. HCW need to be trained for using counselling skills, medication and other tobacco cessation strategies to assist tobacco users quit successfully. ${ }^{39}$

It is established that non-price policies such as stop smoking treatment programmes help smokers quit smoking. Comprehensive cessation policies include financial coverage of treatments, quit lines, and healthcare provider interventions. ${ }^{29}{ }^{40}$ Cessation treatment policies stand-alone increase quit success. However, they may act synergistically with other policies that increase quit attempts, which is what is needed. Though Qatar has been expanding and subsidising stop smoking treatment programmes, however, media campaigns may be needed to publicise cessation programmes. Further increase in outreach activities of HCWs to implement tobacco cessation programmes through training to encourage their patients to quit successfully.
Among the study limitations, HCW in the private healthcare sector were not included in the study. Potential bias could be contributed to the fact that some of our respondents were less likely to be surveyed than others, since it was a voluntary survey, based on self-selection. The vast majority of HCW in Qatar use the internet, however online engagement varies among respondents. However, to reduce sampling bias and non-response bias, we shared our survey through text message, and we sent several survey reminders. The participation in the current online survey was somewhat acceptable similar to what is usually obtained in online surveys $17 \%$ in long version and $25 \%$ in short version ${ }^{41}$ and can reach up to $33.1 \%{ }^{42}$

\section{CONCLUSION}

HCWs in Qatar have somewhat a similar prevalence of tobacco use with no significant increase comparing to earlier studies. Fifty-two per cent of HCW attained an average knowledge score, most of them attained positive attitude scores $(72 \%)$; while almost $60 \%$ provided tobacco cessation interventions to patients. Further training is needed to create a health promoting culture that would contribute to a non-smoking behaviour and 
would increase their competency for a better delivery of tobacco cessation therapy.

\section{Twitter Silva Kouyoumjian @KouyoumjianS}

Acknowledgements We thank the Medical Research Centre in Hamad Medical Corporation in Qatar for funding this research (MRC- Routine grant 01-18-198). The findings achieved herein are solely the responsibility of the authors. We also thank the management of Hamad Medical Corporation and Primary Healthcare Corporation for their support. The authors are also thankful for the IT support provided by Media and Corporate Communications and Health Information and Communications Technology teams at Hamad Medical Corporation in Qatar.

Contributors AA conceived and led the design of the study. SK contributed to the design of the study, conducted data analysis and wrote the manuscript with input from AA. NE contributed to the administrative support of the research project. All authors have read and approved the final manuscript.

Competing interests None declared.

Patient and public involvement Patients and/or the public were involved in the design, or conduct, or reporting, or dissemination plans of this research. Refer to the Methods section for further details.

Patient consent for publication Not required.

Ethics approval The study procedures were approved by the Institute Review Board at the Medical Research Centre in Hamad Medical Corporation in Qatar (01-18-198)

Provenance and peer review Not commissioned; externally peer reviewed.

Data availability statement Data are available on reasonable request.

Open access This is an open access article distributed in accordance with the Creative Commons Attribution Non Commercial (CC BY-NC 4.0) license, which permits others to distribute, remix, adapt, build upon this work non-commercially, and license their derivative works on different terms, provided the original work is properly cited, appropriate credit is given, any changes made indicated, and the use is non-commercial. See: http://creativecommons.org/licenses/by-nc/4.0/.

ORCID iD

Silva Kouyoumjian http://orcid.org/0000-0003-1675-6067

\section{REFERENCES}

1 World Health Organization. The role of health professionals in tobacco control. Geneva: World Health Organization, 2005.

2 Clinical Practice Guideline Treating Tobacco Use and Dependence 2008 Update Panel, Liaisons, and Staff. A clinical practice guideline for treating tobacco use and dependence: 2008 update. A U.S. public health service report. Am J Prev Med 2008;35:158-76.

3 Wray JM, Funderburk JS, Acker JD, et al. A meta-analysis of brief tobacco interventions for use in integrated primary care. Nicotine Tob Res 2018;20:1418-26.

4 World Health Organization. Guidelines for implementation of article 14 of the FCTC. Geneva: World Health Organization, 2010. https:// www.who.int/fctc/Guidelines.pdf?ua $=1$

5 Duaso MJ, McDermott MS, Mujika A, et al. Do doctors' smoking habits influence their smoking cessation practices? A systematic review and meta-analysis. Addiction 2014;109:1811-23.

6 Hasan SI, Mohd Hairi F, Ahmad Tajuddin NA, et al. Empowering healthcare providers through smoking cessation training in Malaysia: a preintervention and postintervention evaluation on the improvement of knowledge, attitude and self-efficacy. BMJ Open 2019;9:e030670.

7 Raupach T, Merker J, Hasenfuss G, et al. Knowledge gaps about smoking cessation in hospitalized patients and their doctors. Eur $J$ Cardiovasc Prev Rehabil 2011;18:334-41.

8 General Secretariat for Development Planning. Qatar national vision 2030. Doha: General Secretariat for Development Planning, 2008. https://www.psa.gov.qa/en/qnv1/Documents/QNV2030_English_v2. pdf

9 World Health Organization. Health professionals survey in the eastern Mediterranean region. regional office for the eastern Mediterranean: World Health organization, 2003. Available: http://apps.who.int/iris/ bitstream/10665/116464/1/dsa808.pdf [Accessed 16 June 2020].

10 Watiri G. Health care providers knowledge, attitude and practice of smoking cessation interventions in public health facilities in Kiambu County, Kenya [thesis]. University of Nairobi, 2014.
11 World Health Organization. Toolkit for delivering the 5A's and $5 R$ 's brief tobacco interventions to $T B$ patients in primary care. Geneva, 2014. http://apps.who.int/iris/bitstream/10665/112836/1/ 9789241506946_eng.pdf?ua=1

12 Andrés A, Castellano Y, Fu M, et al. Exploring individual and contextual factors contributing to tobacco cessation intervention implementation. Addict Behav 2019;88:163-8.

13 Mansoura FI, Abdulmalik MA, Salama RE. Profile of smoking among primary healthcare doctors in Doha, Qatar 2007. Qatar Med J 2010;2010:14.

14 Borgan SM, Jassim G, Marhoon ZA, et al. Prevalence of tobacco smoking among health-care physicians in Bahrain. BMC Public Health 2014;14:931.

15 Al-Lawati JA, Nooyi SC, Al-Lawati AM. Knowledge, attitudes and prevalence of tobacco use among physicians and dentists in Oman. Ann Saudi Med 2009;29:128-31.

16 Shishani K, Nawafleh $\mathrm{H}$, Jarrah S, et al. Smoking patterns among Jordanian health professionals: a study about the impediments to tobacco control in Jordan. Eur J Cardiovasc Nurs 2011;10:221-7.

17 Shaikh S, Aljuraiban G. Prevalence and associated factors of using tobacco products ( $E$ - cigarettes, conventional cigarettes and water pipe) among healthcare workers at the Prince Mohammed bin Abdulaziz hospital in Riyadh, Saudi Arabia, 2018-2019. J Fam Med Dis Prev 2019;5.

18 Nilan K, McKeever TM, McNeill A, et al. Prevalence of tobacco use in healthcare workers: a systematic review and meta-analysis. PLoS One 2019;14:e0220168.

19 Mahfouz AA, Shatoor AS, Al-Ghamdi BR, et al. Tobacco use among health care workers in southwestern Saudi Arabia. Biomed Res Int 2013;2013:960292.

20 Mansour AY. Predictors of smoking among Saudi dental students in Jeddah. Am J Health Behav 2017;41:329-37.

21 Al-Hagabani MA, Khan MS, Al-Hazmi AM, et al. Smoking behavior of primary care physicians and its effect on their smoking counseling practice. J Family Med Prim Care 2020;9:1053-7.

22 AlMulla A, Hassan-Yassoub N, Fu D, et al. Smoking cessation services in the eastern Mediterranean region: highlights and findings from the who report on the global tobacco epidemic 2019. East Mediterr Health J 2020;26:110-5.

23 K Al-Mulla AMA, Bener A. Cigarette smoking habits among Qatari population. Public Health Medicine 2003;4:41-4.

24 El-Awa FMS. Regional summary for the eastern Mediterranean region. Eastern Mediterranean Regional Office: World Health Organization. https://www.who.int/tobacco/global_data/country_ profiles/EMRO_Summary.pdf?ua=1. (accessed 16 June 2020).

25 Hawari FI, Bader RK. Advancing tobacco dependence treatment services in the eastern Mediterranean region: international collaboration for training and capacity-building. Sultan Qaboos Univ Med J 2014;14:e442-7.

26 Alkhatatbeh MJ, Alefan Q, Alzghool M. Smoking prevalence, knowledge and attitudes among primary healthcare professionals: a study from Jordan. East Mediterr Health J 2017;22:872-9.

27 Aveyard P, Begh R, Parsons A, et al. Brief opportunistic smoking cessation interventions: a systematic review and meta-analysis to compare advice to quit and offer of assistance. Addiction 2012;107:1066-73.

28 Zwar NA, Mendelsohn CP, Richmond RL. Supporting smoking cessation. BMJ 2014;348:f7535

29 World Health Organization. Who report on the global tobacco epidemic 2019. Geneva: World Health Organization, 2019.

30 Movsisyan NK, Varduhi P, Arusyak H, et al. Smoking behavior, attitudes, and cessation counseling among healthcare professionals in Armenia. BMC Public Health 2012;12:1028.

31 Mizher IY, Fawaqa SI, Sweileh WM. Prevalence and personal attitudes towards tobacco smoking among Palestinian healthcare professionals: a cross-sectional study. Addict Sci Clin Pract 2018;13:17

32 Wells M, Aitchison P, Harris F, et al. Barriers and facilitators to smoking cessation in a cancer context: a qualitative study of patient, family and professional views. BMC Cancer 2017;17:348.

33 Stead LF, Buitrago D, Preciado N, et al. Physician advice for smoking cessation. Cochrane Database Syst Rev 2013;5:CD000165.

34 Bhat N, Jyothirmai-Reddy J, Gohil M, et al. Attitudes, practices and perceived barriers in smoking cessation among dentists of Udaipur City, Rajasthan, India. Addict Health 2014;6:73-80.

35 Matouq A, Khader Y, Khader A, et al. Knowledge, attitude, and behaviors of health professionals towards smoking cessation in primary healthcare settings. Trans/ Behav Med 2018;8:938-43.

36 Bangera D, Takana M, Muttappallymyalil J. Tobacco cessation: attitude and practice of dentists in northern United Arab Emirates. East Mediterr Health J 2018;24:419-26. 
37 Monshi SS, Halpern MT. Factors associated with smoking cessation and smoking cessation interventions in the Gulf cooperation Council countries. Saudi Med J 2019;40:119-25.

38 Meijer E, van der Kleij R, Segaar D, et al. Determinants of providing smoking cessation care in five groups of healthcare professionals: a cross-sectional comparison. Patient Educ Couns 2019;102:1140-9.

39 Carson KV, Verbiest MEA, Crone MR, et al. Training health professionals in smoking cessation. Cochrane Database Syst Rev 2012;118:CD000214.
40 Levy DT, Tam J, Kuo C, et al. The impact of implementing tobacco control policies: the 2017 tobacco control policy Scorecard. J Public Health Manag Pract 2018;24:448-57.

41 Deutskens E, de Ruyter K, Wetzels M, et al. Response rate and response quality of Internet-based surveys: an experimental study. Mark Lett 2004;15:21-36.

42 Harrison S, Henderson J, Alderdice F, et al. Methods to increase response rates to a population-based maternity survey: a comparison of two pilot studies. BMC Med Res Methodol 2019;19:65. 